\title{
Editorial
}

\section{6th Conference of the German Society for Clinical Microcirculation and Hemorheology}

\author{
M. Jünger ${ }^{\mathrm{a}}$, A. Krüger-Genge ${ }^{\mathrm{b}}$ and F. Jung ${ }^{\mathrm{b}}$ \\ a Department of Dermatology, University Medicine Greifswald, Greifswald, Germany \\ ${ }^{\mathrm{b}}$ Institute of Biomaterial Science and Berlin-Brandenburg Center for Regenerative Therapies, \\ Helmholtz-Zentrum Geesthacht, Teltow, Germany
}

The 36th German Conference for Clinical Microcirculation and Hemorheology has been held at the University Greifswald, 5.-8. June, 2017, organized by Prof. Michael Jünger, PD Dr. G. Daeschlein and Dr. H. Riebe from the Department of Dermatology, University Medicine Greifswald, Greifswald, Germany.

The conference counted with more than hundred participants mainly from Germany but also from Poland, Canada, Switzerland, and the Czech Republic. A high level scientific program was produced with excellent scientific presentations contributing to the increase of knowledge of basic and clinical hemorheology and microcirculation. During fruitful discussions new questions arose and new opportunities of networking initiated. Selected presentations are published in this issue of Clinical Hemorheology and Microcirculation.

The focus of the conference was traditionally oriented to the scientific interests of the society members, which are: physiology and pathophysiology, preclinical and clinical studies, interactions of blood and tissue cells with body foreign surfaces, surgical and conservative therapy of secondary lymph edema, cutaneous microangiopathy of severe vascular diseases as well as the diagnostic value of contrast-enhanced ultrasound. The central features of the conference - according to the profession of the conference President - were diseases of the skin.

In addition, different hands-on workshops were positioned around the scientific program like sclerotherapy of varicosis, endoluminal ablation of varicosis, contrast-enhanced ultrasound for diagnosis in liver, kidney and lymph node malignancies, nailfold capillary microscopy of systemic sclerosis and last but not least clinical applications of low temperature plasma. These workshops were attended mainly by clinicians and linked practical clinical experience to the more scientifically oriented presentations of the conference. The maritime atmosphere of the Baltic Sea was felt by the participants of the meeting particularly during the festive evening which was located in the center of a shipyard near to the harbor of Greifswald. 